\title{
National Ignition Facility SubSystem Design Requirements Final Optics Assembly Subsystem SSDR 1.8.7
}

C. Adams

October 30, 1996

This is an informal report intended primarily for internal or limited external distribution. The opinions and conclusions stated are those of the author and may or may not be those of the Laboratory.

Work performed under the auspices of the U.S. Department of Energy by the Lawrence Livermore National Laboratory under Contract W-7405-Eng-48. 


\section{DISCLAIMER}

This document was prepared as an account of work sponsored by an agency of the United States Government. Neither the United States Government nor the University of California nor any of their employees, makes any warranty, express or implied, or assumes any legal liability or responsibility for the accuracy, completeness, or usefulness of any information, apparatus, product, or process disclosed, or represents that its use would not infringe privately owned rights. Reference herein to any specific commercial product, process, or service by trade name, trademark, manufactures, or otherwise, does not necessarily constitute or imply its endorsement, recommendation, or favoring by the United States Covernment or the University of California. The views and opinions of authors expressed herein do not necessarily state or reflect those of the United States Government or the University of California, and shall not be used for advertising or product endorsement purposes.

This report has been reproduced directly from the best available copy.

Available to DOE and DOE contractors from the Office of Scientific and Technical Information

P.O. Box 62, Oak Ridge, TN 37831

Prices available from (615) 576-8401, FTS 626-8401

Available to the public from the

National Technical Information Service

U.S. Department of Commerce

5285 Port Royal Rd.

Springfield, VA 22161 


\section{National Ignition Facility}

\section{Subsystem Design Requirements}

\section{Final Optics Assembly Subsystem SSDR 1.8.7}

Revision B

30 October, 1996

Prepared by:

C. Adams, Final Optics Assembly Lead Engineer

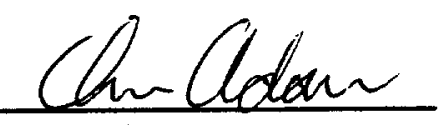

Date $10 / 24 / 96$

Reviewed:

V. Karpenko, Target Experimental System Engineer

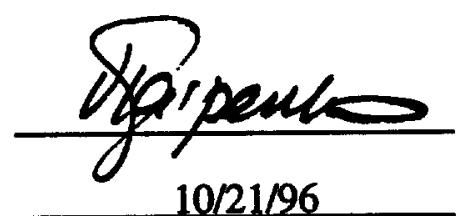

Date

$10 / 21 / 96$

R. Sawicki, NIF Special Equipment APE

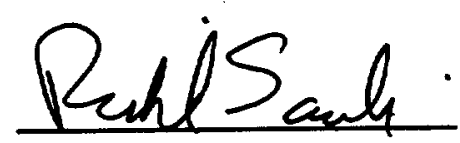

Date $10 / 18 / 96$

Level 4 Configuration Control Board Approval:

S. Kumpan, NIF Project Engineer

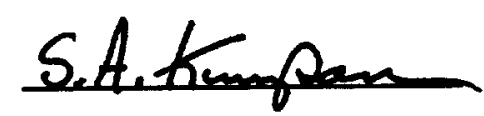
Approval Date $10 / 30 / 96$ 


\section{Table of Contents}

\section{Paragraph}

1.0

2.0

2.1

2.2

2.3

2.4

3.0

3.1

3.1 .1

3.1 .2

3.1.3

3.1.3.1

3.1.4

3.1 .5

3.2

3.2.1

3.2.1.01

3.2.1.02

3.2.1.03

3.2.1.04

3.2.1.05

3.2.1.06

3.2.1.07

3.2.1.08

3.2.1.09

3.2.1.10

3.2.1.11

3.2.1.12

3.2.1.13

3.2 .2

3.2.2.1

3.2.2.1.1

- 3.2.2.1.2

3.2.2.1.3

3.2.2.1.4

3.2.2.1.5

3.2.2.1.6

3.2.2.2

3.2.2.3

3.2.2.5

3.2.3

3.2.3.1

3.2.3.2

3.2.3.2.1

3.2.3.2.2

3.2.3.2.3

3.2.3.2.4

3.2.3.2.5

3.2.3.3
Title

Scope

Applicable Documents

Applicable NIF Project Documents

Applicable US Government Orders, Codes, and Standards

Applicable National Consensus Codes and Standards

Applicable LLNL Standards

Subsystem Description and Characteristics .

System Definition

System Description

System Functions

System Diagrams

System Operating Modes

System Interfaces

Major Subsystems

Subsystem Requirements and Verification

Performance Characteristics

Performance Characteristics - Mounting/ Position of Optical Elements

Performance Characteristics - Alignment/ Adjustability of Optical Elements

Performance Characteristics - Structural Stability

Performance Characteristics - Thermal

Performance Characteristics - Vacuum Compatibility

Performance Characteristics - Cleanliness

Performance Characteristics - Allowable Stress

Performance Characteristics - External Loading

Performance Characteristics - Neutron Activation

Performance Characteristics - Debris Shields - Physical Protection

Performance Characteristics - Debris Shield - Contamination Barrier

Performance Characteristics - Debris Shields- Removal Rate

Performance Characteristics - Vacuum Isolation Valve - Cycle Time

Physical Characteristics of Subsystems

Physical Characteristics - Integrated Optic Module (IOM)

Physical Characteristics - Final Optic Cell (FOC)

Physical Characteristics - FCC Angular Adjustment System (FAAS)

Physical Characteristics - FFL Linear Adjustment System (FLAS)

Physical Characteristics - Debris Shield System (DSS)

Physical Characteristics - Vacuum Window System (VWS)

Physical Characteristics - Thermal Control System (TCS)

Physical Characteristics - Laser Diagnostics

Physical Characteristics - Optical Spacing and Sizes of Elements

Physical Characteristics - Integration of FOA

Reliability, Availability, Maintainability

Lifetime

Replaceability

Replaceability - Integrated Optic Module (IOM)

Replaceability - Debris Shield System (DSS)

Replaceability - 3w Calorimeter Detector

Replaceability - 3w Calorimeter Chamber (3wCC)

Replaceability - Vacuum Isolation Valve

Reliability 


\subsubsection{4}

3.2.3.5

3.2.3.6

3.2 .4

3.2.4.1

3.2 .4 .2

3.2.4.3

3.2.4.4

3.3

3.3.1

3.3.1.1

3.3.2

3.3.2.1

3.3.2.2

3.3.2.3

3.3.2.4

3.4

3.4 .1

3.4 .2

4.0

4.1
Inherent Availability

Maintainability

Recovery from Abnormal Events

Environmental

Environmental - Operating and Transportation

Environmental - Ambient Cleanliness

Environmental - Ambient Random Vibration

Environmental - Shot Characteristics

Design and Construction

Design/ Construction - Hazard Classification

Design/ Construction - Hazards Classification - Natural

Design/ Construction - Safety

Design/Construction - Safety - Life

Design/ Construction - Safety - Laser

Design/ Construction - Safety - Occupational

Design/Construction - Safety - Radiation Protection

Logistics

Spare Equipment

Maintenance Equipment

QA Provisions

Q-Level Assigned 


\subsection{Scope}

This SSDR establishes the performance, design, development and test requirements for the Final Optic Assembly (FOA). The FOA (WBS 1.8.7) as part of the Target Experimental System (1.8) includes vacuum windows, frequency conversion crystals, focus lens, debris shields and supporting mechanical equipment.

\subsection{Applicable Documents}

This section lists NIF Project Documents, DOE and other government orders, codes, and standards, and national consensus standards which are applicable to the FOA Subsystem. Applicable LLNL standards are also being considered contingent upon the decision of final site selection.

\subsection{Applicable NIF Project Documents}

National Ignition Facility Functional Requirements and Primary Criteria, Revision 1.4, L-15983-3, February, 1996

National Ignition Facility System Design Requirements, Laser System SDR002, Revision A, NIF-LLNL-96-228, L-21707-01

National Ignition Facility System Design Requirement 003, Target Experimental System Design Requirements, Revision A, NIF-96-227, L-21706-01

"Proposed Metrication Policy for NIF," memo from R. Sawicki, NIF-LLNL-96-038, L-21248-01, 21 January, 1996

NIF Grounding Plan, NIF-LLNL-94-211, L-17346-1

NIF-LLNL-93-044/L-15958-1, National Ignition Facility Quality Assurance Program Plan, November 1993

Target Emission Group (Tobin, Marshall, et al) papers

Debris Shield Group (Marion, Campbell, et al) papers

\subsection{Applicable US Government Orders, Codes, and Standards}

- 420.1 - Facility Safety

- N441.1 - Protection for DOE Radiological Activities

- 5400.5 - Radiation Protection of the Public and the Environment

- 5700.6C-Quality Assurance

- 5480.9 - Construction Safety and Health Program

- 5480.10 - Contractor Industrial Hygiene Program

- 5480.11 -Radiation Protection for Occupational Workers

\subsection{Applicable National Consensus Codes and Standards}

ASME Boiler and Pressure Vessel Code; Section VIII

\subsection{Applicable LLNL Standards}

LLNL Committee on Metrification, 10 October 1992, "LLNL Metric Transition Path"

LLNL M-012 Rev 7, Feb 1993, "Design Safety Standards -Mechanical Engineering"

LLNL M-010, March 1989, "Health and Safety Manual"

LLNL, M-010 "Hazards Control Manual"

LLNL, M-256 "Mechanical Engineering Design Practice"

LLNL "Mechanical Engineering Policy Procedures Manual"

\subsection{Subsystem Description and Characteristics}




\subsection{System Definition}

This section defines the overall Final Optic Assembly (FOA) as well as subsystems of the FOA to which this SSDR applies. It provides sufficient description of the system configuration and component parts to facilitate understanding of the requirements

\subsubsection{System Description}

The FOA provides for the optical mounting and operational maintenance of resident optics. These optics consist of vacuum windows, frequency conversion crystals, final focus lenses, diffractive optics and debris shields. The FOA interfaces directly to the outer surface of the target chamber. Four beamlines arranged in a $2 \times 2$ quad-array are incorporated into the FOA. With 192 beamlines this results in 48 FOA's populating the surface of the target chamber at prescribed locations. (These location may be found in SDR3, section 3.2.1.1.). In addition to providing mounting for said optical components, precision adjustment capability is required of these optics during operations. These include a precision 2 axis angular positioner at each beamline for the frequency conversion crystals and a z-axis translation capability for the focus lens/ frequency conversion which are mounted in a common cell. Subsystems and components of the FOA must meet design constraints on optical quality, neutron activation, vacuum compatibility, thermal control, cleanliness and operational concerns.

Furthermore, the FOA integrates two laser diagnostic and alignment subsystems. One laser diagnostic package consists of a diffractive grating, turning mirror and calorimeter. The other is an alignment subsystem for each beamline. This subsystem provides for $1 \mathrm{w}$ beam centering and alignment to the frequency conversion crystals. A provisional subsystem being evaluated is a vacuum isolation valve which will allow for the vacuum isolation of the FOA from the target chamber for servicing, maintenance and tasks requiring non-vacuum environment of the FOA while the chamber is at vacuum. This valve would increase the operational flexibility of the NIF. As mentioned previously, there is a requirement for a debris shields at the output side of the final optic assembly. These shields are to provide physical protection to the other optical elements of the FOA. Debris maybe in the form of projectiles and plasma emanating from the target region, the chamber walls, beam dumps and any other source in the chamber (diagnostics, inserters, etc). These shields are expected to be replaced often and so a means to allow for the rapid replacement is required to be designed into the system. Another element to be packaged with the debris shield is a beam smoothing optic. This is to address the need operational need of rapidly changing the phase plate characterisitc based on shot requirements. Other elements or subsystem of the FOA will also require scheduled and unscheduled maintenance and the FOA and subsystems are to be designed for replacement at a rate consistent with the overall NIF availability requirement.

\subsubsection{System Functions}

The FOA converts $1 \mathrm{w}$ light to the third harmonic through use of a type $\mathrm{V} / \mathrm{type}$ II KDP/ KD*P frequency conversion crystals which are mounted within an integrated optic module which in turn is attached to the target chamber through the $3 w$ calorimeter chamber. Figure 3.1.2 is a schematic illustration of one of the four beamlines of the FOA. Each beamline first passes through a vacuum window, then on through the frequency conversion crystals (FCC), a final focus lens and finally through the debris shield before focus is achieved at chamber center. In addition provisions will be made for $3 w$ calorimetry as well as beam centering alignment at the FCC. All of these subsystem need to operate in reliable manner consistent with the general overall reliability of the system. Also replaceable units should be designed to minimize the down-time of NIF. In summary the FOA is to perform the following functions:

$\$$

\%

4

*

*

$*$

Convert a $1 \mathrm{w}(1053 \mathrm{~nm})$ beam to a $3 \mathrm{w}(351 \mathrm{~nm})$ beam

Focus the $3 \mathrm{w}$ light onto a common focal area near the target chamber center Disperse the residual $1 w$ and $2 w$ light away from the target laser entrance hole (LEH) Provide required spot envelope at target Provide for the mounting of the frequency conversion crystal, focus lens, debris shield and any diffractive optic included in the design Provide a vacuum barrier for the target chamber Provide the necessary mounting for laser diagnostics consisting of a $3 \mathrm{w}$ calorimeter and a $1 \mathrm{w}$ beam centering system Provide thermal management for the frequency converter crystals 


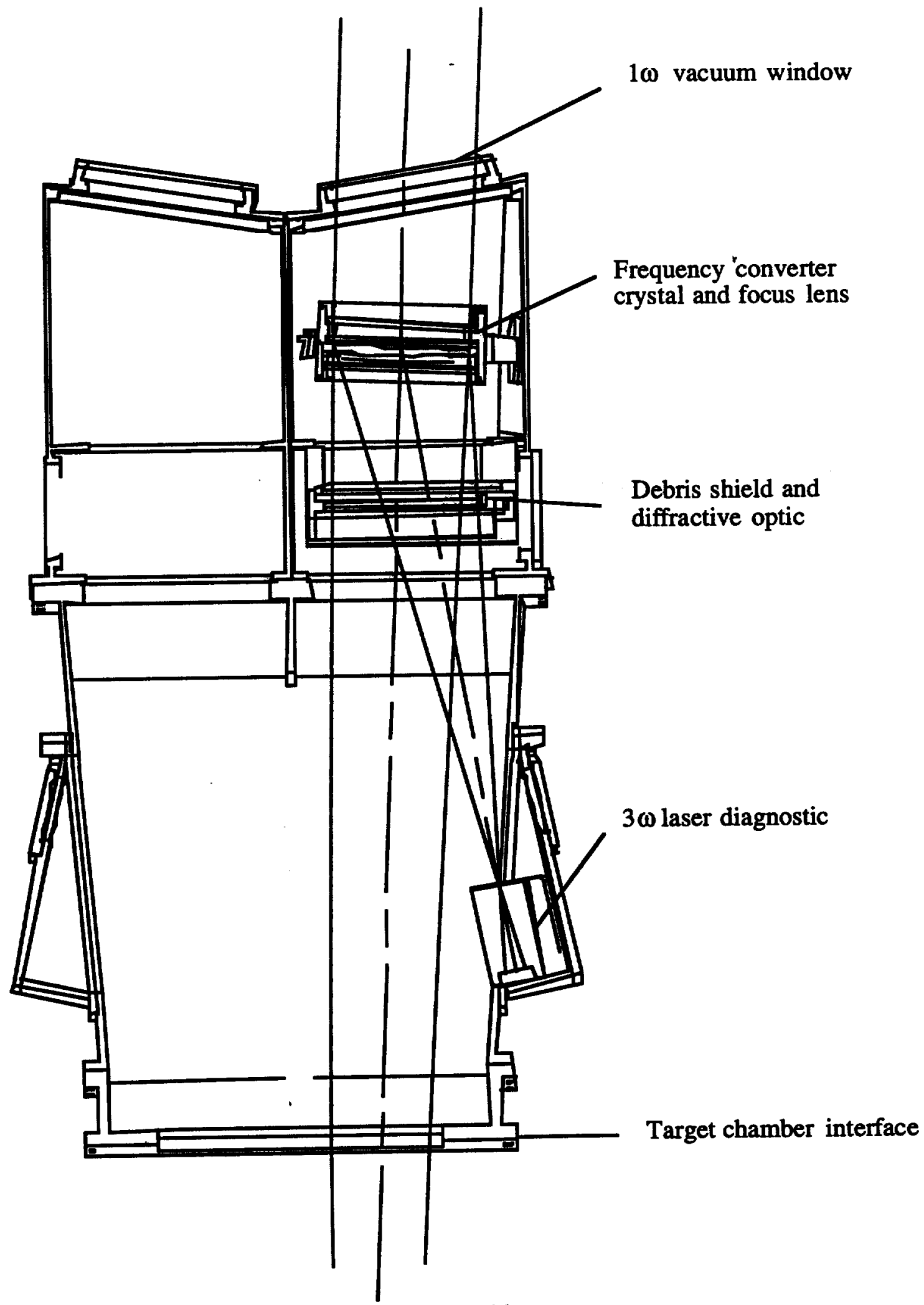

Figure 3.1.2: Schematic illustration of the Final Optic Assembly 


\subsubsection{System Diagrams}

A cutaway isometric view of the FOA with major functional elements is shown in figure 3.1.3.

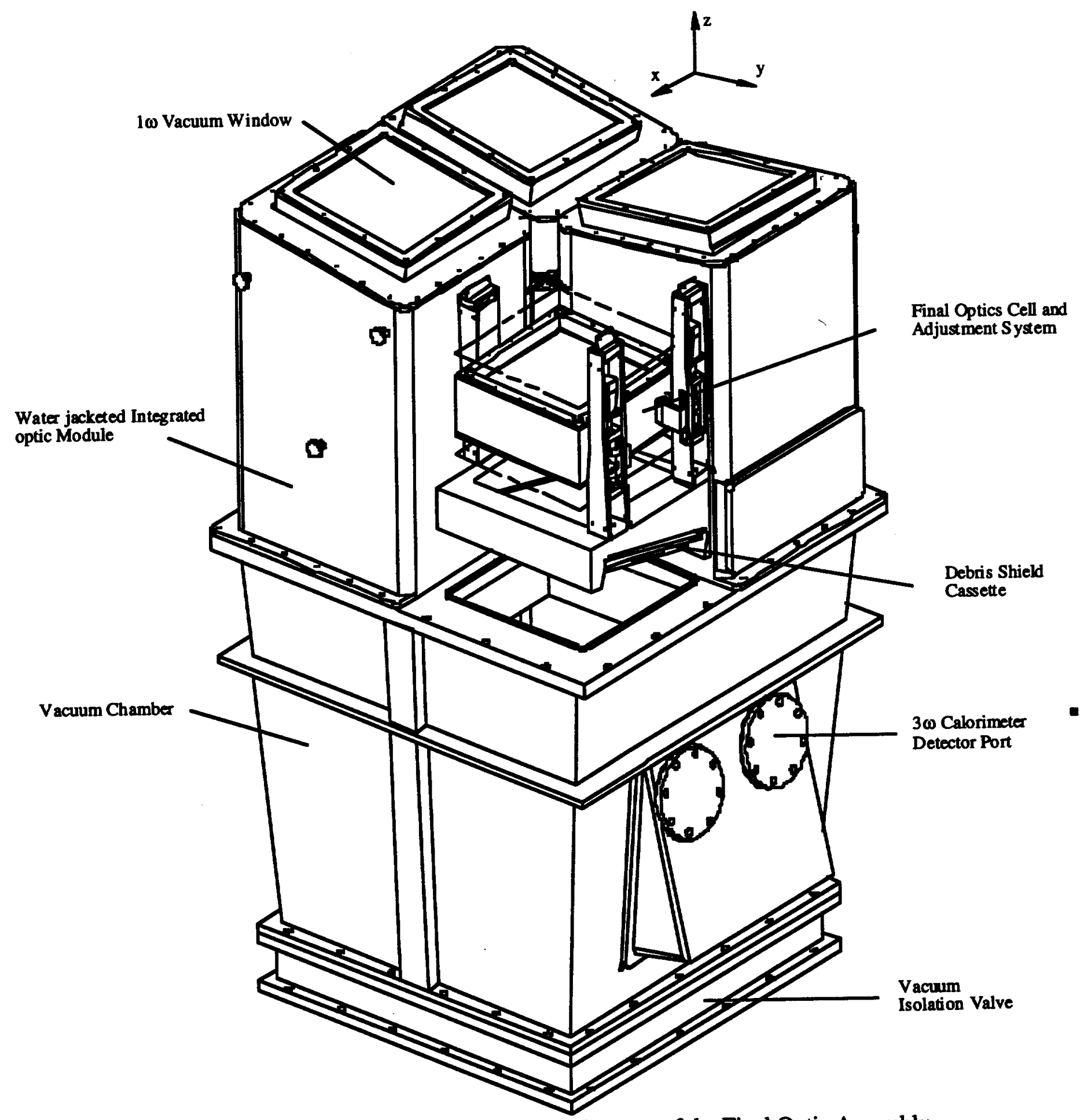

Figure 3.1.3: An isometric view of the functional elements of the Final Optic Assembly 


\subsubsection{System Operating Modes}

Figure 3.1.3.1-1 identifies the sequence of operating modes planned for the NIF facility. The FOA's as part of the Target Experimental Systems will also operate in all these modes, following the same scenario as the overall facility.

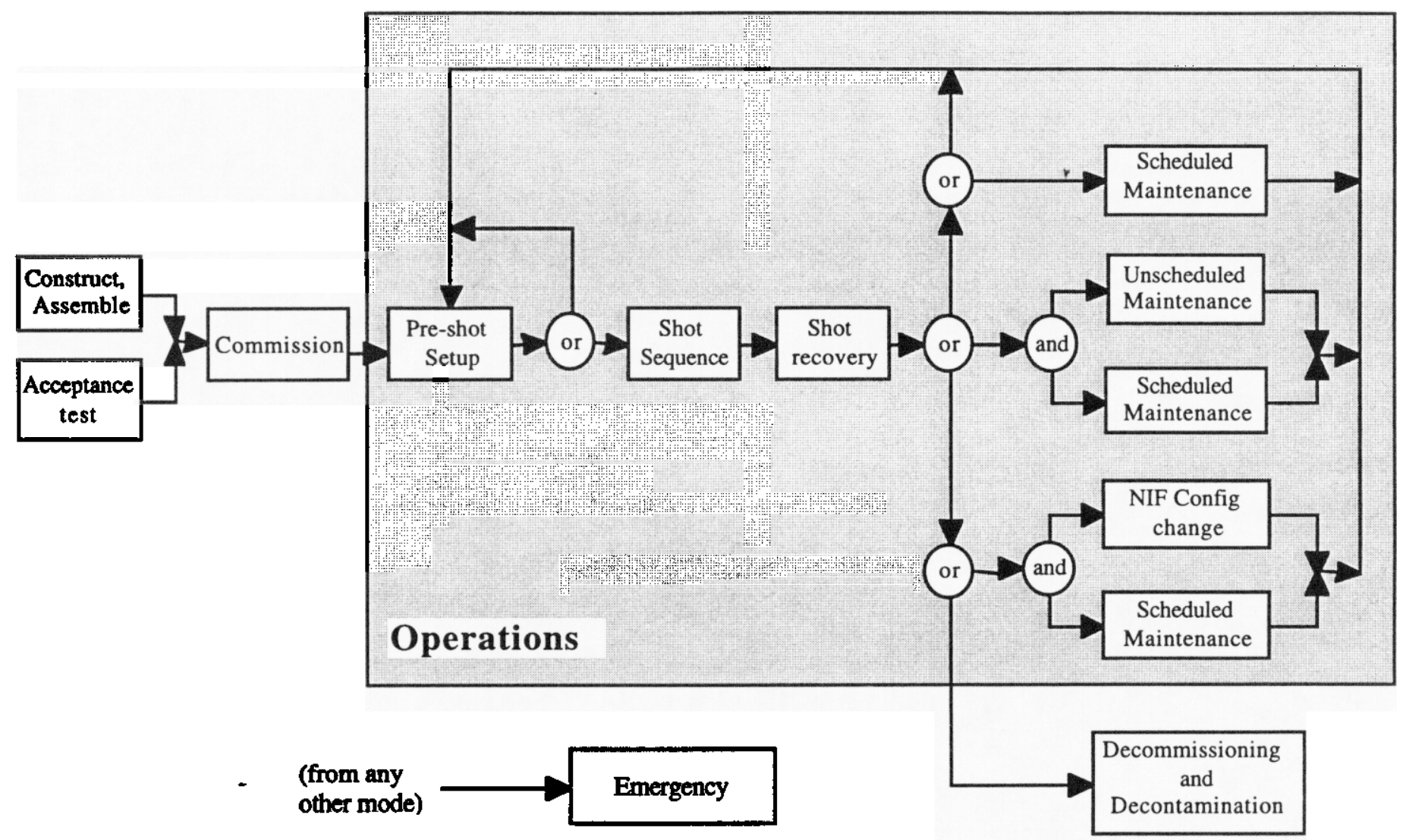

Figure 3.1.3.1-1 NIF operating modes

\subsubsection{System Interfaces}

The FOA has the following interfaces with other subsystems of the NIF:

WBS 1.2.2.2 Target Area Building: The FOA reside within the target building, they require environmental control of the air surrounding the FOA's, an access space to permit operation and maintenance functions.

WBS 1.2.2.3 Optical Assembly Building: The FOA's as they are to be assembled, internally aligned and refurbished within $\mathrm{OAB}$. Clean space in a controlled environment will be provided by the $\mathrm{OAB}$.

WBS 1.5 Integrated Computer Control System (ICCS): Alignment, inspection, temperature/ pressure control and safety interlocks will all be controlled or verified through the ICC.

WBS 1.6 Optical Components: The FOA's provide mounting, alignment and adjustment of resident optical elements. In addition to the interfacing with the physical size of these element the FOA design will be consistent with the general processing and handling plan.

WBS 1.7 Laser Control: The functionality of the FOA's directly couple to laser control system by providing feedback for alignment as well as wavefront quality control. 
WBS 1.8.1 Target Chamber: The FOA's mount directly to the outside of the target chamber. The FOA and target chamber share the same vacuum space and vacuum system. The target chamber must provide a stable optical platform for the FOA.

WBS 1.8.3 Target Diagnostic: The FOA's share the same surface of the chamber sphere as target diagnostic

WBS 1.8.4 Target Structure: The primary interface with this WBS element are the beamtubes which mount to input surface of the FOA.

WBS 1.8.5 Environmental Protection Systems: Components of the FOA, particularly the debris shields will be decontaminated by the EPS on a routine basis.

\subsubsection{Major Subsystems}

As described previously (section 3.1) the FOA consist of mechanical subsystems which are comprised of, or are integrated with optical elements or thermal/mechanical subsystems which perform the appropriate tasks to meet system design requirements. The optical elements which are to mounted, aligned, adjusted and thermally controlled are the following:

1. Frequency Conversion crystals (FCC)

2. Final focus lens (FFL)

3. Diffractive optic (DO)

4. Debris shields (DS)

5. $1 \mathrm{w}$ vacuum window $(\mathrm{VW})$

Subsystems of the FOA which are considered either mechanical or thermal subsystems are listed below followed by an acronym which will be used throughout the course of this SSDR. Figure 3.1.5 indicates where these subsystems are located within the FOA.

1. The integrated optic module (IOM), which is further comprised of:

a. Final optic cell (FOC), provide mounting for optical elements consisting of FCC, FFL and DO.

b. FCC angular adjustment system (FAAS), allows for angular adjustment of the conversion crystals.

c. Final focus lens adjustment system (FLAS), allows for focus adjustment of the lens.

d. Debris shield system (DSS), provides for insertion, mounting and retrieval of shields.

e. Vacuum window system (VWS), provide a vacuum barrier to the target chamber.

f. FCC thermal control system (TCS), provides thermal control for the conversion crystals.

2. Structures/ vacuum chambers

a. Integrated optic module chamber (IOMC), a vacuum chamber which houses FOA subsystems.

b. $3 w$ calorimeter chamber ( $3 w C C)$, a vacuum chamber which houses the $3 w$ calorimeter system

3. Laser diagnostics

a. $3 w$ calorimeter system ( $3 w C S)$, provides for energy measurement of the $3 w$ beam.

b. $1 \mathrm{w}$ beam centering system (1wBCS), allows for alignment of the $1 \mathrm{w}$ beam.

4. Vacuum isolation valve (VIV), allow maintenance of FOA subsystems at atmospheric conditions. 


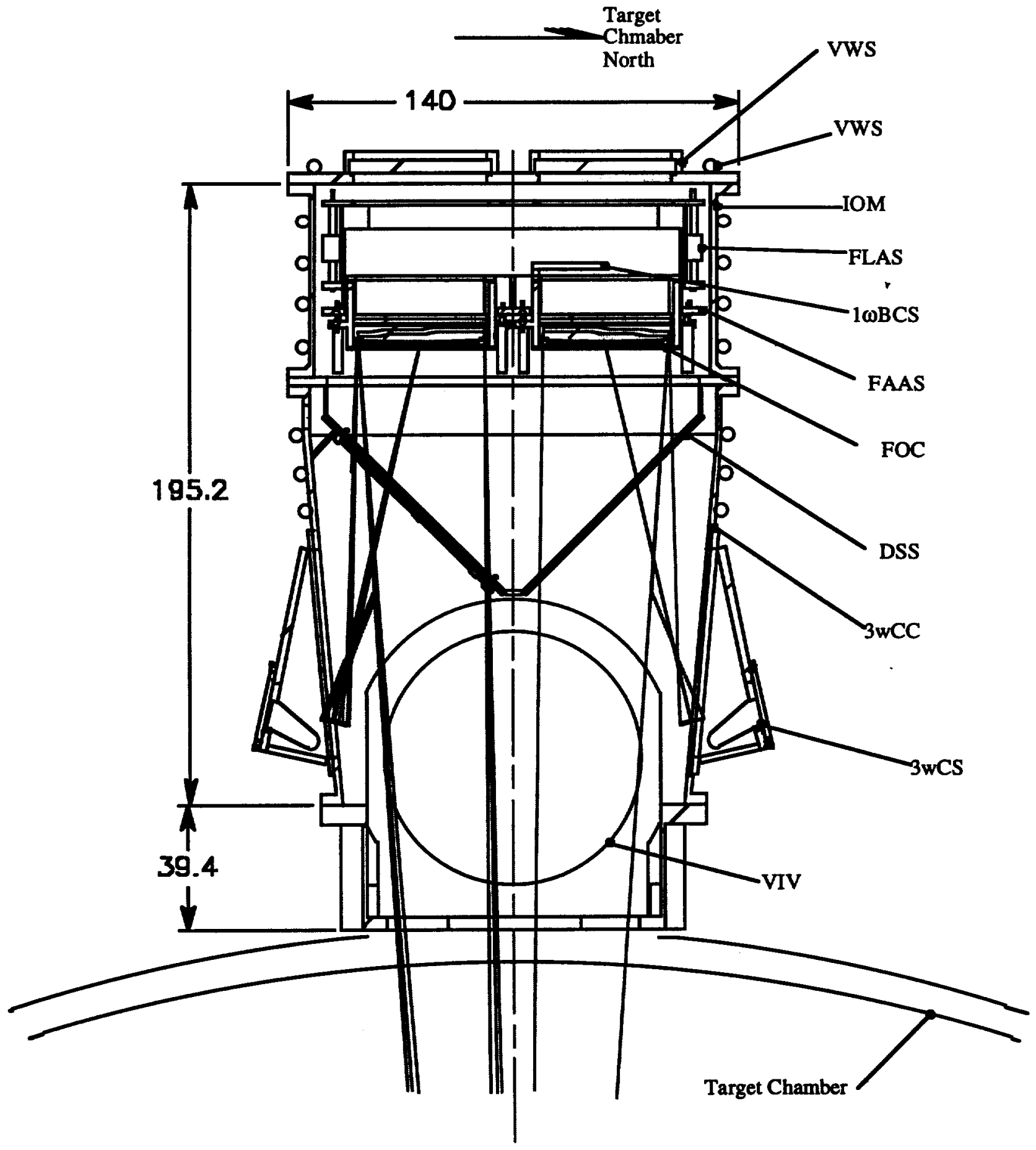

Fig 3.1.5: Subsystems of the FOA identified.

\subsection{Subsystem Requirements and Verification}

The following sections define the minimum requirements which must be met by the Final Optic Assembly related to performance, physical characteristics, etc. The approach for verifying that the design and the hardware meets each requirement is listed for each. 


\subsubsection{Performance Characteristics}

This section describes the performance characteristics of thermal/mechanical subsystems of the FOA as described in section 3.1.5. The following table lists the performance characteristics associated witheach of the identified components.

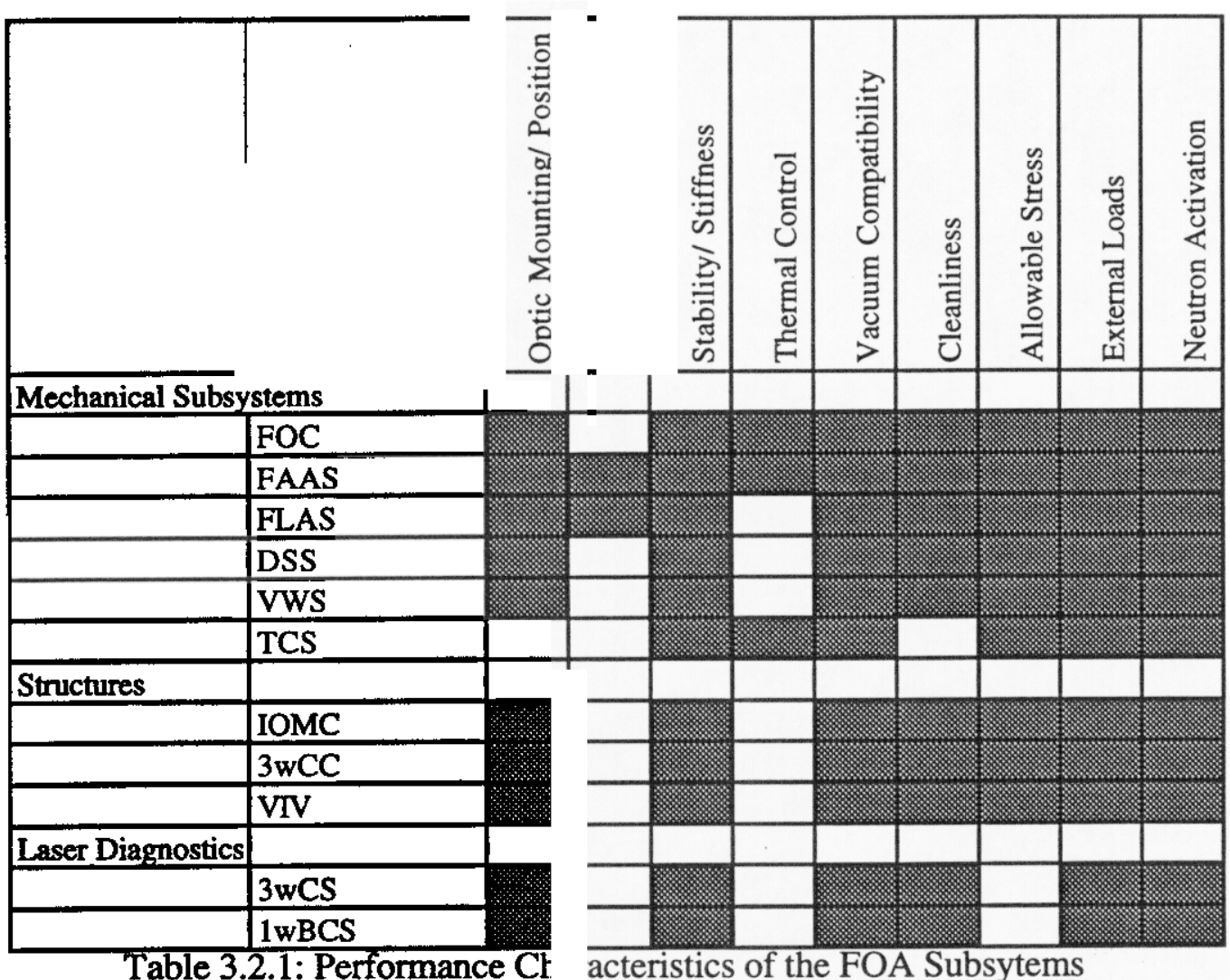

\subsubsection{Performance Characteristics - Mounting/ Position of Optical Elements}

The FOA houses the optical elements described in section 3.1.5. The alignment of these elements can be considered to broken into two parts. The first is the location or position of these elements with respect to each other. The second part is the tolerance on that position. The following table identifies what these values are for the optical elements of the FOA. The coordinate system used is shown in figure 3.1.3. 
Table 3.2.1.01: Alignment criteria for FOA optical elements

(refer to figure 3.1.3 for description of coordinate system)

This table indicates the position of the final optic elements as they are assembled in the OAB with respect to a common reference.

The position values listed are referenced in the FOA - Optics Configuration drawing (AAA96-104900),

\begin{tabular}{|c|c|c|c|c|c|c|}
\hline & \multicolumn{6}{|c|}{ Position (mm or mrad) } \\
\hline $\begin{array}{l}\text { Optical } \\
\text { Component }\end{array}$ & $\mathbf{x}$ & $\mathbf{y}$ & $\mathbf{z}^{1}$ & $\theta \mathrm{x}$ & $\theta y$ & $\theta \mathbf{z}$ \\
\hline $\begin{array}{l}\text { Vacuum } \\
\text { Window }^{2}\end{array}$ & 0 & 0 & 7473 & 0 & & 0 \\
\hline $\mathrm{SHG}^{3}$ & $\mathbf{0}$ & $\overline{0}$ & 7035 & 0 & 10 & 0 \\
\hline THG & $\mathbf{0}$ & $\overline{0}$ & 7019 & $\overline{0}$ & 10 & $\overline{0}$ \\
\hline $\begin{array}{l}\text { Final Focus } \\
\text { Lens }^{3}\end{array}$ & 0 & 0 & 7000 & $\overline{0}$ & $\overline{0}$ & $\overline{0}$ \\
\hline $\begin{array}{l}\text { Diffractive } \\
\text { Optic }^{3}\end{array}$ & $\mathbf{0}$ & $\overline{0}$ & 6645 & $\overline{0}$ & 10 & $\overline{0}$ \\
\hline Debris Shield ${ }^{2}$ & $\overline{0}$ & $\overline{0}$ & 6625 & 0 & 0 & $\overline{0}$ \\
\hline & \multicolumn{6}{|c|}{$+/$ - Tolerance (mm or urad) } \\
\hline $\begin{array}{l}\text { Optical } \\
\text { Component }\end{array}$ & $\mathbf{x}$ & $\mathbf{y}$ & $\mathbf{z}$ & $\theta \mathrm{x}$ & $\theta y$ & $\theta \mathbf{z}$ \\
\hline $\begin{array}{l}\text { Vacuum } \\
\text { Window }\end{array}$ & 3 & 3 & 3 & 5000 & 5000 & 5000 \\
\hline $\mathrm{SHG}^{3,4,5}$ & 2 & 2 & $\overline{2}$ & 20 & 20 & 5000 \\
\hline $\mathrm{THG}^{3.4 .}$ & 2 & 2 & $\overline{2}$ & 20 & 20 & 5000 \\
\hline $\begin{array}{l}\text { Final Focus } \\
\text { Lens }^{3}\end{array}$ & 0 & 0 & 0 & 0 & $\overline{0}$ & 5000 \\
\hline $\begin{array}{l}\text { Diffractive } \\
\text { Optic }^{3}\end{array}$ & 3 & 3 & 3 & 10000 & 10000 & 10000 \\
\hline Debris Shield ${ }^{2}$ & 3 & 3 & $\overline{3}$ & 30000 & 30000 & 30000 \\
\hline
\end{tabular}

Notes:

1: These dimensions are at the input surface of the optical element with the origin at target chamber center.

2: These elements are not part of the final optic cell (FOC). Will be located through repeatable intermediate interfaces

3: These elements are assembled within the FOC, therefore can be located accurately with respect to each other.

4: SHG/THG tolerance includes crystal cutting errors, FOC fabrication tolerance, assembly tolerance, and off-line alignment

5: These numbers have been validated by tolarance study referenced in FOC Tolerance Study (NIF \#' jiij-kkkk-11I))

\subsubsection{Performance Characteristics - Alignment/ Adjustability of Optical Elements}

As described in the text of 3.1.5 the FCC and the FLL have to be actively aligned or adjusted to the beamline during operation use. This is be accomplished with the FAAS and and the FLAS. The performance requirements of these subsystems is outlined in the following table. 
Table 3.2.1.02: Adjustement requirement for the FAAS and FLAS

(refer to figure 3.1.3 for description of coordinate system)

This table indicates the alignment ranges, accuracies and resolutions of the final optic elements as they are automatically aligned during operations.

\begin{tabular}{|c|c|c|c|c|c|c|}
\hline & \multicolumn{6}{|c|}{$+/$ - Range (mm or $\mathrm{mrad})$} \\
\hline Optical Component & $\mathbf{x}$ & $\mathbf{y}$ & $\mathbf{z}$ & $\theta \mathbf{x}$ & $\theta y$ & $\theta z$ \\
\hline Final Optic Cell ${ }^{1}$ & 0 & $\overline{0}$ & $50^{2}$ & $20^{3}$ & $20^{3}$ & 0 \\
\hline
\end{tabular}

\begin{tabular}{|l|c|c|c|c|c|c|}
\hline & \multicolumn{6}{|c|}{+ - Accuracy (mm or urad) } \\
\hline Optical Component & $\mathrm{x}$ & $\mathrm{y}$ & $\mathrm{z}$ & $\theta \mathrm{x}$ & $\theta \mathrm{y}$ & $\theta \mathrm{z}$ \\
\hline Final Optic Cell & $0.1^{4}$ & $0.1^{4}$ & 0.3 & 5 & 5 & $\mathrm{n} / \mathrm{a}$ \\
\hline
\end{tabular}

\begin{tabular}{|l|c|c|c|c|c|c|}
\hline & \multicolumn{6}{|c|}{+ -Resolution (mm or urad) } \\
\hline Optical Component & $\mathrm{x}$ & $\mathrm{y}$ & $\mathrm{z}$ & $\theta \mathrm{x}$ & $\theta \mathrm{y}$ & $\theta \mathrm{z}$ \\
\hline Final Optic Cell & $\mathrm{n} / \mathrm{a}$ & $\mathrm{n} / \mathrm{a}$ & 0.1 & 2 & 2 & $\mathrm{n} / \mathrm{a}$ \\
\hline
\end{tabular}

Notes:

1: The Final Optic Cell houses the SHG, THG, focus lens.

2: This is a minimum motion; Allow for center of travel as well as tolerance build-up from chamber interface.

3: This is motion allowance for fabrication tolerance on the target chamber and FOA assemblies.

4: This number maybe allowed to be larger over full range of travel, dependent on alignment procedure.

\subsubsection{Performance Characteristics - Structural Stability}

As shown in table 3.2.1 all subsystems of the FOA have to meet a mechanical stability requirement. The requirement is the position of the FFL shall not move more then $6 \mu \mathrm{m}$ laterally when subject external loadinbg consisting of random vibration input as well as thermal loads. The random vibration input is applied at the base of the target chamber pedestal. The level of vibrational input is specified as a power spectral density curve of $10^{-10}$ $\mathrm{g}^{2} / \mathrm{Hz}$ from 1 to $200 \mathrm{~Hz}$. In addition the FCC shall not be displaced rotationally more the $\left.5 \mu \mathrm{rad}\right)$. Other potential sources to be considered are acoustic sources (air ventilation) or ancillary hardware which may be required in and around the FOA (ie water cooling for the conversion crystals).

\subsubsection{Performance Characteristics - Thermal}

The primary thermal requirement is for the FCC. The TCS will meet the following requirements.

1) The TCS shall be capable of controlling the absolute temperature of the FCC crystals between $19.7 \mathrm{C}$ and 20.3C to within $+/-0.1 C$ (TBD).

2) The TCS shall hold the temperature of each crystal uniformly to $+1-0.1 \mathrm{C}$ over the entire crystal.

3) The temperature of each crystal shall be held for a $2 \mathrm{hr}$ time period starting with start of alignment sequence to shot time.

4) The TCS shall be designed to cool the FCC to acceptable levels within a $2 \mathrm{hr}$ time period. 
5) The design shall not preclude the possibility of an increase shot rate of $4 \mathrm{hr}$ which would result in an approximately $1 \mathrm{hr}$ time window to maintain crystal temperature.

Additional consideration shall be given to internal sources of heat such as motors and actuators.

\subsubsection{Performance Characteristics - Vacuum Compatibility}

As shown in table 3.2.1 all subsystems of the FOA have to meet a vacuum compatibility requirement. These subsystems shall be designed to operate in a vacuum environment of $5 \times 10^{\wedge}-5$ torr. Outgassing of internal surface shall be minimized. The mechanical design, fabrication techniques and material selection shall be done with due consideration of the requirement.

\subsubsection{Performance Characteristics - Cleanliness}

As shown in table 3.2.1 all subsystems of the FOA have to meet a cleanliness requirement. These subsystems shall be designed to operate and be compatible with a level 100 cleanliness specified in MIL -STD-1246C. Material selection, fabrication techniques and design choices shall be made with due consideration. Additionally all optical surfaces shall be maintained at level 50 except for the debris shield which is subjected to debris and emission from the target chamber.

Maintenance of cleanliness shall be provided during expected routine operations which will be performed on debris shields and other larger subsystems such as the the Integrated Optic Module.

\subsubsection{Performance Characteristics - Allowable Stress}

As shown in table 3.2.1 some of the subsystems of the FOA have to meet a stress requirement.

The mechanical design of these subsystems shall be based on the yield strength of ductile material or the ultimate strength of brittle materials. The factors of safety applied for peak stresses shall follow applicable LLNL design guides as well as any relevant industry or trade association code or rules except as noted. Some designs (notably the vacuum chambers) may require a buckling analysis, in this case the chamber shall be treated as an externally pressurized vessel and is covered under ASME Boiler and Pressure Vessel Code.

Note: The vacuum window shall be designed to minimize the maximum tensile stress of the glass window to less then 500 psi.

\subsubsection{Performance Characteristics - External Loading}

As shown in table 3.2.1 some of the subsystems of the FOA have to meet an external loading requirement. These loadings along with the design response are the following: 1) External atmospheric load; the FOA subassemblies subject to this loading condition will experience deformations and distortions. These deformation shall not unduly influence or impair the ability of these subsystems to meet there performance requirements. 2) Seismic load; the FOA and subsystems shall be designed to withstand a seismic input at the base of the target chamber pedestal (as specified in SDR003 section 3.3.01.2) consistent with a planned downtime of the overall facility (as specified in SDR003 sectiion 3.2.3.5). 3) Random vibration input. (Please see section 3.2.1.01 of this SSDR).

\subsubsection{Performance Characteristics - Neutron Activation}

The design of all subsystem shall minimize the level of neutron activation. Material selection, choice of location of particular components of the subsystem shall be done with due consideration of the neutron environment consistent with section 3.3.2.6 (Safety - Radiation Protection)

\subsubsection{Performance Characteristics - Debris Shields - Physical Protection}

The debris shields shall protect the other optical elements of the FOA from plasma and vaporized target material generated from the target region. 


\subsubsection{Performance Characteristics - Debris Shield - Contamination Barrier}

The debris shield shall provide a means to control the amount of tritium which is allowed to reach the final optics as well as other subsystems located within the IOM. A design goal to keep the activation of tritium on surfaces to less then $100 \mathrm{dpm} / \mathrm{cm} 2$.

\subsubsection{Performance Characteristics - Debris Shields- Removal Rate}

The debris shield removal system shall be designed to allow the safe and efficient manual removal of debris shields from the IOM. The DSS should allow for the removal to be accomplished in less then $1 \mathrm{hr}$ time for the four debris shields per FOA.

\subsubsection{Performance Characteristics - Vacuum Isolation Valve - Cycle Time}

The VIV shall be designed to reduce the time associated with opening and closing the valve but done in manner consistent other design consideration (reliability and cleanliness). It is a design goal to allow the valve to be closed, opened and closed again within a TBD (provisional 2 minute) time frame.

\subsubsection{Physical Characteristics of Subsystems}

This section describes the physical nature of the identified subsystems of the FOA. These characteristic include parameters such as size, mass and general spacing requirements and limitations.

\subsubsection{Physical Characteristics - Integrated Optic Module (IOM)}

As described previously the IOM consists of:

1. Final optic cell (FOC)

2. FCC Angular adjustment system (FAAS)

3. Final focus lens adjustment system (FLAS)

4. Debris shield system (DSS)

5. Vacuum window assembly (VWS)

6. Thermal Control System (TCS)

The outer housing of the IOM is the IOM chamber (IOMC). It shall provide vacuum housing in which to mount and attach the subsystem described above. The overall size of the chamber shall be consistent with these requirements as well as be sized so as to eliminate interferences with other hardware which is mounted on the surface of the target chamber, particulary other FOA's, target diagnostics and ancillary support equipment. The IOMC shall be designed with fixtures to aid and allow for the safe and efficient transport and handling of the IOM.

\subsection{Physical Characteristics - Final Optic Cell (FOC)}

The following are the pertinent physical characteristic of the FOC:

1. The FOC shall be designed large to enough to house resident optics yet fit within the IOM structure.

2. The FOC shall be designed with a mechanical hard aperture of $40 \mathrm{~cm} \times 40 \mathrm{~cm}$ with $0.5 \mathrm{~cm}$ (TBD) corner radii. This aperture shall be located in front of the frequency conversion crystals.

3. The mechanical hard aperture shall be made of material which can withstand the intensity, wavelength and power of the NIF beamline.

4. The mounting of the FCC within the FOC shall be allowed with a $0.5 \mathrm{~cm}$ margin around the perimeter of the crystal

\subsection{Physical Characteristics - FCC Angular Adjustment System (FAAS)}

The following are the pertinent physical characteristic of the FAAS:

1. The FAAS shall be designed to carry the load of a single FOC and perform its required adjustment functions. 
2. The FAAS shall be designed to not interfere with other FAAS's or other hardware within the IOM.

3. It is a design goal to allow for the local control of the alignment system for the FCC. This local control shall be in compliance with standard/procedure set forth by the ICC.

\subsection{Physical Characteristics - FFL Linear Adjustment System (FLAS)}

The following are the pertinent physical characteristic of the FLAS:

1. The FLAS shall be designed to carry the load of 4 FOC's and 4 FAAS's and perform its required adjustment functions.

2. The FLAS shall be designed to not interfere with the DSS or other hardware within the IOM and 3wCC.

3. The nominal physical spacing of the four beamlines as described by a plane containing the midpoint of the final focus lenses shall be the following:

s_long $=50.6 \mathrm{~cm}$ (provisional)

s_latitude $=57.5 \mathrm{~cm}$ (provisional)

(please refer to figure 3.2.2.1.3 for calarification of the dimensions)

4. It is a design goal to allow for the local control of the alignment system for the FCC. This local control shall be in compliance with standard/procedure set forth by the ICC

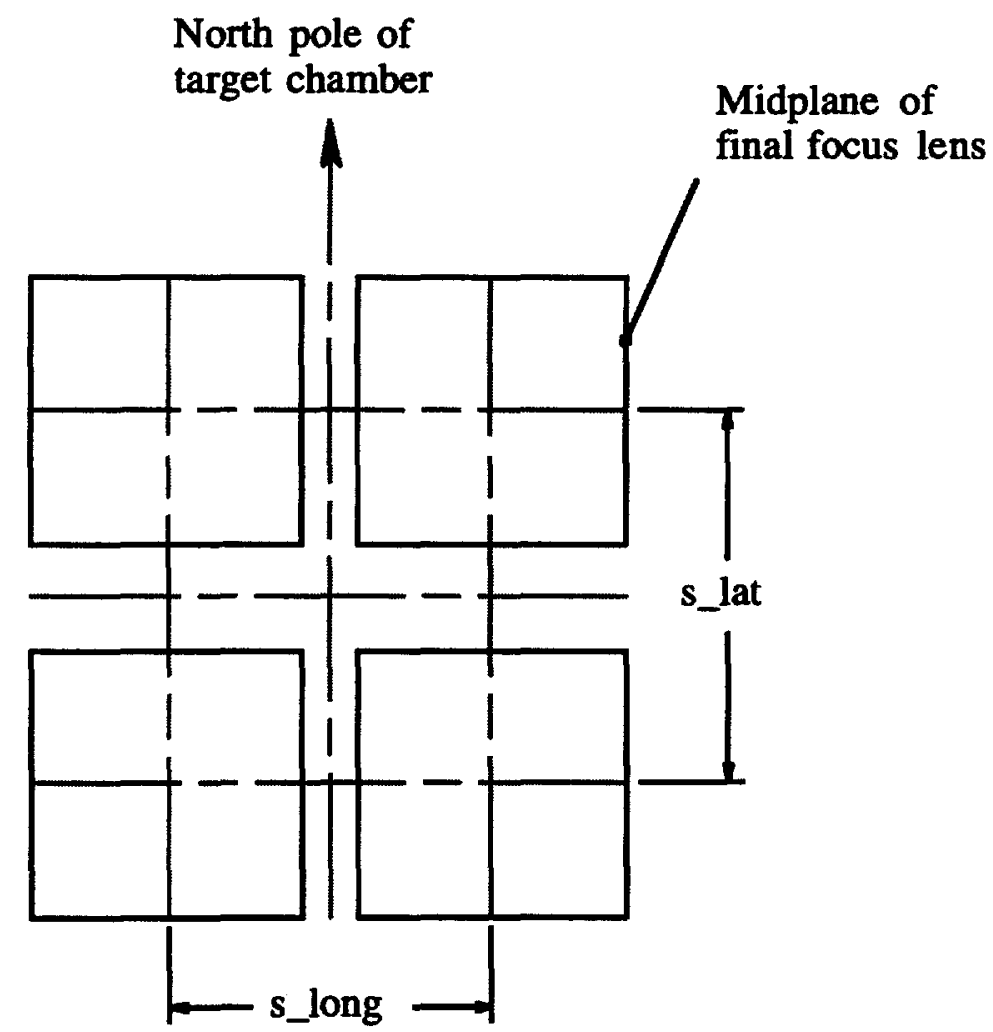

Figure 3.2.2.1.3: Center to center spacing of final optics focus lens

\subsection{Physical Characteristics - Debris Shield System (DSS)}

The following are the pertinent physical characteristic of the DSS: 


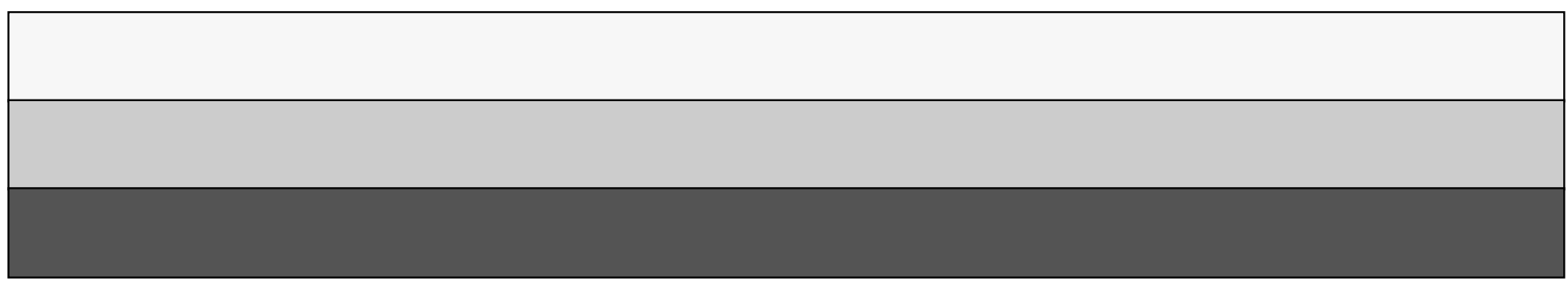

